\title{
Considerations for Elderly People Facing Colorectal Surgery
}

\author{
Bode Rovena* \\ Department of General Surgery, "Mother Teresa” University Hospital Center, Albania
}

*Corresponding author: Rovena B, Department of General Surgery, “Mother Teresa” University Hospital Center, Rruga e Dibres, 1025Tirana, Albania

Submission: 眥 August 29, 2017; Published: 眥 November 16, 2017

\begin{abstract}
Age is a powerful risk factor for development of colorectal cancer but is not a contraindication for surgery, although this surgery is characterised by poor outcomes, increasing morbidity and mortality. Contributing factors include their poor nutritional status, pre-existing comorbidity, polypharmacy, psychosocial issues, delayed diagnoses and frailty. To improve morbidity and mortality, several aspects of care need to be addressed. These include accurate and timely preoperative assessment to identify treatable pathology and, where possible, to consider and correct age specific disease processes. Identification of patients in whom treatment would be futile or associated with high risk is needed to avoid unnecessary interventions and to give patients realistic expectations. Therefore, by the creation of a multidisciplinary approach, where surgeons work side by side with anesthesiologists, geriatricians, physiotherapists, nutritionists and other professionals, can provide favourable surgical outcomes, through improved selection of candidates for intervention and a more considered exclusion of patients characterized by high risk profiles or a poor prognosis.
\end{abstract}

Keywords: Aging population; Frailty; Risk assessment

Abbreviations: CRC: Colorectal Cancer; APR: Abdomino Perianal Resection; LAR: Low Anterior Resection; TUG: Time Up and Go; ADLs: Activities of Daily Living; QoL: Quality of Life

\section{Introduction}

Across the globe, populations are getting older [1] and with aging, the incidence and prevalence of cancer increases [2,3]. Currently, $60 \%$ of malignant disease occurs in persons over 65 years of age. More than half of these patients are over 70 years old and $25 \%$ are over 80 years old [2]. Furthermore, elderly patients are more likely to present as emergencies and this also confers increased risk [3]. For example, for patients over 75, over $40 \%$ require emergent treatment [4]. It has recently been demonstrated that the highest risk of being diagnosed with CRC is between 80 and 89 years of age; thus, in future, CRC will constitute a major problem for health care systems [5,6].

The intrinsic reduction in tolerance to stressors, the frequent presence of one or more medical disorders in addition to the cancer, polypharmacy and delayed diagnoses increase the risk of a poor surgical outcome in elderly patients undergoing cancerrelated surgery. Therefore, by the creation of a multidisciplinary approach, where surgeons work side by side with anesthesiologists, geriatricians, physiotherapists, nutritionists and other professionals, can provide favourable surgical outcomes [7], through improved selection of patients for intervention and a more considered exclusion of patients characterized by high risk or a poor prognosis.

\section{General considerations on colorectal cancer surgery in the elderly}

Table 1:

\begin{tabular}{|c|c|c|}
\hline Group & Age & Goals \\
\hline \multicolumn{3}{|l|}{ Entering old age } \\
\hline $\begin{array}{l}\text { Completed their } \\
\text { career in paid } \\
\text { employment and/ } \\
\text { or child rearing } \\
\text { Are active and } \\
\text { independent and } \\
\text { many remain so into } \\
\text { late old age }\end{array}$ & $\begin{array}{l}\text { Includes people as } \\
\text { young as } 50 \text { years old. } \\
\text { or from the official } \\
\text { retirement ages of } 60 \\
\text { for women and } 65 \text { for } \\
\text { men }\end{array}$ & $\begin{array}{l}\text { Promote and extend } \\
\text { healthy active life } \\
\text { Compress morbidity } \\
\text { (the period of } \\
\text { life before death } \\
\text { spent in frailty and } \\
\text { dependency) }\end{array}$ \\
\hline \multicolumn{3}{|l|}{ Transitional phase } \\
\hline $\begin{array}{l}\text { In transition between } \\
\text { healthy, active life and } \\
\text { frailty }\end{array}$ & $\begin{array}{l}\text { This transition often } \\
\text { occurs in the seventh } \\
\text { or eighth decades of } \\
\text { life but can occur at } \\
\text { any stage of older age }\end{array}$ & $\begin{array}{l}\text { Identify emerging } \\
\text { problems ahead of } \\
\text { crisis Ensure effective } \\
\text { responses that will } \\
\text { prevent crisis and } \\
\text { reduce long-term } \\
\text { dependency }\end{array}$ \\
\hline
\end{tabular}




\begin{tabular}{|c|c|c|}
\hline Frail older people & & \\
\hline $\begin{array}{c}\text { These people are } \\
\text { vulnerable as a result } \\
\text { of health problems } \\
\text { such as stroke or } \\
\text { dementia. social } \\
\text { care needs. or a } \\
\text { combination of both }\end{array}$ & $\begin{array}{c}\text { Frailty is often } \\
\text { in late old age, so } \\
\text { services for older } \\
\text { people should be } \\
\text { designed with their } \\
\text { needs in mind }\end{array}$ & $\begin{array}{c}\text { Anticipate and } \\
\text { respond to problems. } \\
\text { Recognizing the } \\
\text { complex interaction } \\
\text { of physical mental. } \\
\text { And social care } \\
\text { factors. which } \\
\text { can compromise } \\
\text { independence and } \\
\text { quality of life }\end{array}$ \\
\hline
\end{tabular}

The World Health Organization defines old age as 60 years and over, although in poorer countries with lower life expectancy than in developed countries, ages as low as 50-55 years can be used [8]. In the UK, old age is classified into 3 stages shown in Table 1 , reflecting how disease state and physiological deterioration can affect different individuals in different ways. This continuum of old age progresses from fit and healthy through to frailty.

A formal nutritional assessment is valuable in the per operative assessment of elderly patients. Elderly patients may have poor nutritional status because of either poor intake due to the underlying illness or pre-existing comorbid conditions. In the outpatient setting, it is estimated that $9 \%$ to $15 \%$ of persons $>65$ years old are malnourished. This increases to $12 \%$ to $50 \%$ and $25 \%$ to $60 \%$ in the acute inpatient hospital setting and chronic institutional settings, respectively. The cycle of frailty that occurs with chronic under nutrition or malnutrition can lead to progressive functional decline, loss of muscle mass, and decreased metabolic rate in this population. Poor nutrition can lead to increased nosocomial infections, multiorgan system dysfunction; poor wound healing, and impaired functional recovery. It is estimated that $40 \%$ of elderly hospitalized patients with cancer are at risk of malnutrition, which has been found to be associated with prolonged hospital stays, and increased morbidity and mortality in patients undergoing elective gastrointestinal surgery. Sungurtekin [9] preoperatively assessed the nutritional status in 100 patients undergoing major abdominal surgery using different assessment tools and found that malnourished patients were at a higher risk of complications. Similar findings were observed among gastrointestinal cancer patients [10]. Regarding CRC patients, Mohri [11] found that malnutrition was an independent predictor of poor survival (OR=2.04; 95\%CI: 1.39-3.09) and was significantly correlated with the incidence of postoperative complications, especially serious ones, in a cohort of 365 patients (171 patients $>65$ years old).

Multimorbidity, defined as the occurrence of multiple diseases in the same individual, often affects older patients with CRC and is one of the major predictors of surgical morbidity, mortality and survival. They commonly have associated cardiovascular and respiratory problems or some other co-morbid condition that may influence a decision on their suitability for surgery. The severity of these co-morbid conditions increases with age and will have a negative impact on surgical outcome of colorectal cancer. Regarding survival, a retrospective study of a cohort of 29733 patients, 67 years of age or older with a primary diagnosis of stage I-III CRC showed that comorbidities exert a substantial influence on survival as the predicted 5-year survival in patients with stage I CRC and comorbidities was approximately $50 \%$ vs $78 \%$ for patients with stage I cancer without comorbidities [12].

Zingmond [13] found that, of 56621 CRC patients undergoing tumor resection, those with a higher Charlson comorbidity index (CCI) were significantlyassociated with postoperative complications. Disability is a crucial predictor of a poor postoperative outcome. It is a multifactorial process of physiological changes, which results in loss of functional ability such as mental capacity, mobility, and daily activities. Cancer patients defined as being functionally dependent according to the validated instrumental activity of daily living were found to have a 2 to 3 -fold increased risk of postoperative morbidity compared with those defined as independent [14].

Attention has to be drawn towards elderly psychosocial issues for example, patients can become disoriented, feel socially isolated, and suffer anxiety and depression. Their presence has been associated with an increased risk of mortality and poor surgical outcome [15]. Hu [16] have recently examined the role of dementia on surgical outcome in 207693 patients 60 years of age or older who underwent inpatient major surgery. Particular problem in the elderly population which impact on surgical care is the potential delay in surgical treatment due to a missed or delayed diagnosis secondary to an atypical presentation of disease, atypical signs or symptoms, such as a lack of fever or atypical presentation mimicking appendicitis, anemia, absence of signs of intra abdominal sepsis which means delayed interventions, and increased morbidity.

Another objective of preoperative evaluation is definition of patients characterized by frailty. Campbell \& Buchner [17] gave a definition for frailty as "a condition or syndrome which results from a multisystem reduction in reserve capacity to the extent that a number of physiological systems are close to, or past, the threshold of symptomatic clinical failure". Key elements of frailty include the following: unintentional weight loss, self-reported exhaustion, weakness (reduced grip strength and other factors), slow walking speed, and low physical activity. Frailty is a syndrome associated with advanced age that results from decreased physiologic reserve and which makes patients less resistant to major stressors such as invasive surgical procedures. Frail patients are prone to poorer outcomes, due to falls, disability, impaired ability to perform activities of daily living (ADLs), prolonged hospitalizations and an increase in mortality. Studies focusing on older patients undergoing elective cardiac and non-cardiac surgery estimate the prevalence rates of frailty to vary from $41.8 \%$ to $50.3 \%$ [18]. Regarding CRC surgery, a recent study has found that CGA was able to predict surgical morbidity in a cohort of 178 elderly CRC patients where the CGA-defined group of frail individuals was found to be significantly associated with severe complications $(\mathrm{OR}=3.13$; 95\%CI: 1.65 5.92) $[19,20]$.

Rapid tools have been developed with the aim of quickly identifying frail patients [21-23]. Among the above-mentioned tools, the timed up and go (TUG) test, a test used to assess a 
person's gait speed and mobility, seems to be the most promising [24]. Poor performance on this test correlates with the presence of other aspects of frailty; thus, its use as a rapid and simple means of stratifying preoperative risk in the elderly seems reasonable. Since its introduction, several studies have pointed out a clear correlation between a prolonged TUG and poor functional status, cognitive impairment and fall risk [25].

Furthermore, a slower TUG test has recently been demonstrated to predict postoperative complications, $30-\mathrm{d}$ readmission, institutionalization and 1-year mortality in a cohort of 272 elderly patients undergoing elective surgery [26]. Patient perspective and expectations is essential in establishing a proper understanding of the QoL goals and achieving good postoperative outcomes for senior adults with CRC. Mental and physical health seemed to be interrelated in both young and senior adults with cancer as reported by weaver, affecting their perspective regarding their disease and the expectations as to the cure they were undergoing. Among the possible stressors, having a stoma has been historically considered as a factor which increases psychological distress in patients with CRC. This fact has also been reconsidered in the past few years. A large meta-analysis on the impact of a stoma forming procedure abdominal perineal resection (APR) vs low anterior resection (LAR)] on 1443 patients with CRC failed to show a reduction in the QoL of patients with fecal diversion. The mean age in the two groups was $66.3 \pm 6$ and $65.6 \pm 6$ years for APR and LAR, respectively [27]. This important finding was again confirmed by a smaller but more recent study from the Netherlands where no difference was seen in terms of health-related QoL, emotional function and understanding of the illness among elderly rectal cancer patients with or without a stoma [27]. This may indicate that having a stoma and the risk of incontinence are considered equally troublesome for patients.

Data seem to suggest that disability and lack of independence are considered more important than the cancer diagnosis per se. The risk of postoperative disability, and not just the risk of having a fecal diversion, needs to be fully discussed with patients and family with the goal of promoting faster functional recovery. It is now accepted that age per se is not a contraindication for surgery in colon cancer patients [28], even if it is still hard to overcome the general thinking that a less aggressive and radical approach should be provided for this population $[28,29]$. It is well known that elderly patients have an increased number of comorbidities which leads to a higher rate of morbidity and mortality . It is the influence of these factors which lead to under treatment with consequent poorer outcomes as demonstrated in a study performed by Chang et al in a group of 21390 patients identified in the Surveillance, Epidemiology, and End Results database (1991-2002). The authors found a decreased use of multimodal treatment, an increased use of local excision and a decreased use of radical surgery. Another study by Dekker [30] described a population-based analysis of 9397 stage I-III CRC patients operated on in the Netherlands from 1991 to 2005. They showed that decreased survival in the elderly is mainly due to differences in early mortality. Elderly CRC patients who survived the first year had the same cancer-related survival as younger patients; therefore, treatment of elderly CRC patients should focus on perioperative care and the first postoperative year [31].

\section{Surgical considerations on CRC in elderly}

The role of surgery in advanced CRC is limited. Guidelines from the National Comprehensive Cancer Network recommend that patients with stage IV CRC should undergo surgery only if they are symptomatic (e.g., bleeding, obstruction, perforation) or have a potentially resectable metastatic localization.

In recent years, several studies have evaluated the feasibility of liver resection for colorectal metastases. Liguori [32] analyzed data from 181 liver resections performed on 178 consecutive senior adult patients. The overall survival rate at 5 years was $31.5 \%$. Similar results were reported by Nagano [33] who reported $34.1 \%$ 5-year survival in 202 elderly patients undergoing surgery for CRC liver metastatic disease. An interesting study evaluated the outcome of liver surgery for colorectal metastases in patients over 70 years of age in a large international multicenter cohort [34]. The elderly were compared to a younger population, and a higher rate of 60 -d postoperative mortality and morbidity was found but, surprisingly, the 3-year survival rate was similar in the two groups ( $57.1 \%$ vs $60.2 \%$ for elderly and younger patients, respectively). Liver resection for CRC metastases in elderly patients can achieve a reasonable survival rate.

Approximately $20 \%$ of colorectal cancer cases present as an emergency often necessitating emergency treatment. A systematic review of literature from the year 2000 of the management of colorectal cancer in elderly patients found increased emergency presentation, more advanced disease stage at presentation, and increased morbidity and mortality with increasing age of note, comorbidity was a weak discriminator of the patients who were offered surgery, suggesting age alone may be the driver in surgical decision-making processes. Obstruction is a frequent presentation of advanced disease, in the elderly population [35]. Right colon cancer only rarely presents with obstructing symptoms and, in those cases, surgical treatment is almost always needed. In contrast, left colon cancer is more frequently responsible for bowel obstruction at presentation and its management has been the subject of debate. Several studies have been undertaken to evaluate non-surgical strategies in malignant left-sided large bowel obstruction.

Self-expanding metal stents (SEMS) have been proposed since 1991 as a bridge solution to relieve acute symptoms, improve clinical conditions and allow patients to receive elective surgical procedures and to possibly avoid a stoma. Some retrospective analyses have suggested that the use of SEMS in the elderly population is an effective and safe therapeutic option compared with primary emergency surgery [36] for both elderly and younger patients [37]. On the other hand, two randomized trials tried to evaluate whether colonic stenting improved patient outcomes compared with emergency surgery, but neither managed to define a decisive clinical advantage $[38,39]$. 
Despite the fact that individuals over 75 years of age comprise $8 \%-10 \%$ of the overall population, $35 \%-45 \%$ of patients with rectal cancer fall into this subgroup of patients, with an incidence of approximately 135 new cases per 100000 people in the group from 80 to 85 years of age [40-42]. Surgery is still the cornerstone for the treatment of these patients. Regardless of the increased risk of postoperative complications, 5-year cancer-specific mortality is comparable to that of younger patients, emphasizing the similarity of the intrinsic prognosis of the disease $[43,44]$. Two interesting multicenter studies have confirmed that the increase in postoperative morbidity and mortality (from $0.5 \%$ in patients under 50 years of age to $13 \%$ in patients over 80 years of age) is not related to age per se $[45,46]$.

As expected, according to the American Society of Anaesthesiology (ASA) score, emergency surgery, low rectal cancer and advanced tumor stage were responsible for the higher number of postoperative complications. Unfortunately, elderly people with advanced cancer and in a setting of several comorbidities are more prone to undergo emergency surgery [47]. This amount of evidence reinforces the idea that age is not an indication of a poor prognosis but that biological age. Since low rectal cancer is related to an increased risk of complications, interest has been drawn towards understanding the impact of age on postoperative complications. Two studies by Rutten $[40,48]$, analyzing postoperative complications in elderly patients from a dutch trial, pointed out an unusual finding: anastomotic leak risk was about $10 \%$ in people over 75 years of age and $12 \%$ in younger patients $(\mathrm{P}=0.63)$ but, after $6 \mathrm{mo}$, more than half of the elderly patients (57.1\% vs $8.2 \%$ ) who experienced an anastomotic complication died. Six-month mortality was $22.9 \%$ overall vs $7.0 \%$, (relative risk: 3.27; 95\% CI: 2.05-5.21) among elderly patients who had a postoperative complication (e.g., sepsis, abscess, cardiac and pulmonary complications) compared with younger patients. Once more, this finding demonstrates that postoperative complications are not tolerated very well by elderly patients, therefore, pointing out the importance of accurately monitoring the postoperative course in these patients $[49,50]$.

From a study in Japan [51], early adjuvant chemotherapy can improve the survival of patients with advanced colorectal cancer, among patients 75 years of age or older with stage III CRC, 35\% with colon cancer and $21 \%$ with rectal cancer received adjuvant therapy. Also patients with completely respected stage III colon cancer have an overall survival benefit from adjuvant chemotherapy. Meanwhile from a Cancer Care Ontario Systematic Review [52], combination chemotherapy (5fluorouracil/leucovorin/ oxaliplatin or capecitabine/oxaliplatin) provides a larger benefit than monotherapy but with additional toxicity.

\section{Conclusion}

Although, evidence has shown that colorectal surgery in elderly patients have poor outcomes, there are specific strategies to improve the care received by this vulnerable group. Surgeons cannot achieve this change alone but in cooperation with emergency physicians, geriatricians, anesthetists, critical care specialists, specialist nurses, therapists, and dieticians, through improved selection of candidates for intervention and a more considered exclusion of patients characterized by high risk or a poor prognosis.

\section{References}

1. Ferrucci L, Giallauria F, Guralnik JM (2008) Epidemiology of aging. Radiol Clin North Am 46(4): 643-652.

2. Siegel R, Naishadham D, Jemal A (2013) Cancer statistics, 2013. CA Cancer J Clin 63(1): 11-30.

3. Balducci L (2005) Epidemiology of cancer and aging. J Oncol Manag 14(2): 47-50.

4. Koperna T, Kisser M, Schulz F (1997) Emergency surgery for colon cancer in the aged. Arch Surg 132(9): 1032-1037.

5. Ugolini G, Rosati G, Montroni I, Zanotti S, Manaresi A, et al. (2009) Can elderly patients with colorectal cancer tolerate planned surgical treament A practical approach to a common dilemma. Colorectal Dis 11(7): 750-755.

6. Papamichael D, Audisio R, Horiot JC, Glimelius B, Sastre J, et al. (2009) Treatment of the elderly colorectal cancer patient: SIOG expert recommendations. Ann Oncol 20(1): 5-16.

7. Terret C, Zulian GB, Naiem A, Albrand G (2007) Multidisciplinary approach to the geriatric oncology patient. J Clin Oncol 25(14): 18761881.

8. WHO Definition of an older or elderly person.

9. Sungurtekin H, Sungurtekin U, Balci C, Zencir M, Erdem E (2004) The influence of nutritional status on complications after major intraabdominal surgery. J Am Coll Nutr 23(3): 227-232.

10. Kuzu MA, Terzioğlu H, Genç V, Erkek AB, Ozban M, et al. (2006) Preoperative nutritional risk assessment in predicting postoperative outcome in patients undergoing major surgery. World J Surg 30(3): 378390.

11. Mohri Y, Inoue Y, Tanaka K, Hiro J, Uchida K, et al. (2013) Prognostic nutritional index predicts postoperative outcome in colorectal cancer. World J Surg 37(11): 2688-2692.

12. Gross CP, Guo Z, McAvay GJ, Allore HG, Young M, et al. (2006) Multimorbidity and survival in older persons with colorectal cancer. J Am Geriatr Soc 54(12): 1898-1904.

13. Zingmond D, Maggard M, O'Connell J, Liu J, Etzioni D, et al. (2003) What predicts serious complications in colorectal cancer resection. Am Surg 69(11): 969-974.

14. Kristjansson SR, Jordhøy MS, Johannessen HO, Nesbakken A, Skovlund E, et al. (2010) Which elements of a comprehensive geriatric assessment (CGA) predict postoperative complications and early mortality after colorectal cancer surgery. J GeriatrOncol 1(2): 57-65.

15. Extermann M, Hurria A (2007) Comprehensive geriatric assessment for older patients with cancer. J Clin Oncol 25(14): 1824-1831.

16. Hu CJ, Liao CC, Chang CC, Wu CH, Chen TL (2012) Postoperative adverse outcomes in surgical patients with dementia: a retrospective cohort study. World J Surg 36(9): 2051-2058.

17. Campbell AJ, Buchner DM (1997) Unstble disability and the fluctuations of frailty. Age Ageing 26(4): 315-318.

18. Makary MA, Segev DL, Pronovost PJ, Syin D, Bandeen-Roche K, et al. (2010) Frailty as a predictor of surgical outcomes in older patients. J Am Coll Surg 210(6): 901-908.

19. Partridge JS, Harari D, Dhesi JK (2012) Frailty in the older surgical patient: a review. Age Ageing 41(2): 142-147. 
20. Kristjansson SR, Nesbakken A, Jordhøy MS, Skovlund E, Audisio RA, et al (2010) Comprehensive geriatric assessment can predict complications in elderly patients after elective surgery for colorectal cancer: a prospective observatinal cohort study. Crit Rev Oncol Hematol 76(3): 208-217.

21. Overcash JA, Beckstead J, Moody L, Extermann M, Cobb S (2006) The abbreviated comprehensive geriatric assessment (aCGA) for use in the older cancer patient as a prescreen: scoring and interpretation. Crit Rev OncolHematol 59(3): 205-210.

22. Mohile SG, Bylow K, Dale W, Dignam J, Martin K, et al. (2007) A pilot study of the vulnerable elders survey-13 compared with the comprehensive geriatric assessment for identifying disability in older patients with prostate cancer who receive androgen ablation. Cancer 109(4): 802-810.

23. Slaets JP (2006) Vulnerability in the elderly: frailty. Med Clin North Am 90(4): 593-601.

24. Podsiadlo D, Richardson S (1991) The timed "Up \& Go": a test of basic functional mobility for frail elderly persons. J Am Geriatr Soc 39(2): 142148.

25. Savva GM, Donoghue OA, Horgan F, O’Regan C, Cronin H, et al. (2013) Using timed up-and-go to identify frail members of the older population. J Gerontol A BiolSci Med Sci 68(4): 441-446.

26. Bossema ER, Seuntiëns MW, Marijnen CA, Baas-Thijssen MC Velde CJ, et al. (2011) The relation between illness cognitions and quality of life in people with and without a stoma following rectal cancer treatment. Psychooncology 20(4): 428-434.

27. Gabriel SE, Normand SL (2012) Getting the methods right--the foundation of patient-centered outcomes research. N Engl J Med 367(9): 787-790.

28. Aparicio T, Navazesh A, Boutron I, Bouarioua N, Chosidow D, et al. (2009) Half of elderly patients routinely treated for colorectal cancer receive a sub-standard treatment. Crit Rev Oncol Hematol 71(3): 249-257.

29. Damhuis RA, Wereldsma JC, Wiggers T (1996) The influence of age on resection rates and postoperative mortality in 6457 patients with colorectal cancer. Int J Colorectal Dis 11(1): 45-48.

30. Dekker JW, Broek CB, Bastiaannet E, Geest LG, Tollenaar RA, et al. (2011) Importance of the first postoperative year in the prognosis of elderly colorectal cancer patients. Ann Surg Oncol 18(6): 1533-1539.

31. Faivre J, Lemmens VE, Quipourt V, Bouvier AM (2007) Management and survival of colorectal cancer in the elderly in population-based studies. Eur J Cancer 43(15): 2279-2284.

32. Liguori Carino DN, Leeuwen VBL, Ghaneh P, Wu A, Audisio RA, et al (2008) Liver resection for colorectal liver metastases in older patients. Crit Rev Oncol Hematol 67(3): 273-278.

33. Nagano Y, Nojiri K, Matsuo K, Tanaka K, Togo S, et al. (2005) The impact of advanced age on hepatic resection of colorectal liver metastases. J Am Coll Surg 201(4): 511-516.

34. Adam R, Frilling A, Elias D, Laurent C, Ramos E, et al. (2010) Liver resection of colorectal metastases in elderly patients. Br J Surg 97(3): 366-376.

35. Guo MG, Feng Y, Zheng Q Di JZ, Wang Y, et al. (2011) Comparison of self-expanding metal stents and urgent surgery for left-sided malignant colonic obstruction in elderly patients. Dig Dis Sci 56(9): 2706-2710.

36. Donnellan F, Cullen G, Cagney D, O'Halloran P, Harewood GC, et al. (2010) Efficacy and safety of colonic stenting for malignant disease in the elderly. Int J Colorectal Dis 25(6): 747-750.
37. Pirlet IA, Slim K, Kwiatkowski F, Michot F, Millat BL (2011) Emergency preoperative stenting versus surgery for acute left-sided malignant colonic obstruction: a multicenter randomized controlled trial. SurgEndosc 25(6): 1814-1821.

38. Hooft VJE, Bemelman WA, Oldenburg B, Marinelli AW, Holzik MF, et al. (2011) Colonic stenting versus emergency surgery for acute left-sided malignant colonic obstruction: a multicentre randomised trial. Lancet Oncol 12(4): 344-352.

39. Cheung HY, Chung CC, Tsang WW, Wong JC, Yau KK, et al. (2009) Endolaparoscopic approach vs conventional open surgery in the treatment of obstructing left-sided colon cancer: a randomized controlled trial. Arch Surg 144(12): 1127-1132.

40. Rutten HJ, den Dulk M, Lemmens VE, Velde CJ, Marijnen CA (2008) Controversies of total mesorectal excision for rectal cancer in elderly patients. Lancet Oncol 9(5): 494-501.

41. Jung B, Påhlman L, Johansson R, Nilsson E (2009) Rectal cancer treatment and outcome in the elderly: an audit based on the Swedish Rectal Cancer Registry 1995-2004. BMC Cancer 9: 68.

42. Elferink MA, Krijnen P, Wouters MW, Lemmens VE, Jansen-Landheer ML, et al. (2010) Variation in treatment and outcome of patients with rectal cancer by region, hospital type and volume in the Netherlands. Eur J SurgOncol 36 (Suppl 1): S74-82.

43. Calle PLJ, Quayle J, Thaler HT, Shi W, Paty PB, et al. (2000) Favorable short-term and long-term outcome after elective radical rectal cancer resection in patients 75 years of age or older. Dis Colon Rectum 43(12): 1704-1709.

44. Damhuis RA, Wiggers T, Wereldsma JC (1997) Association between age and local recurrence of rectal cancer: results from a retrospective study of 902 patients. Int J Colorectal Dis 12(4): 235-239.

45. Endreseth BH, Romundstad P, Myrvold HE, Bjerkeset T, Wibe A, et al. (2006) Rectal cancer treatment of the elderly. Colorectal Dis 8(6): 471479.

46. Barrier A, Ferro L, Houry S, Lacaine F, Huguier M (2003) Rectal cancer surgery in patients more than 80 years of age. Am J Surg 185(1): 54-57.

47. Alves A, Panis Y, Mathieu P, Kwiatkowski F, Slim K, et al. (2005) Mortality and morbidity after surgery of mid and low rectal cancer. Results of a French prospective multicentric study. Gastroenterol Clin Biol 29(5): 509-514.

48. Abel GA, Shelton J, Johnson S, Elliss-Brookes L, Lyratzopoulos G (2015) Cancer-specific variation in emergency presentation by sex, age and deprivation across 27 common and rarer cancers. Br J Cancer 112(Suppl): 129-136.

49. Millan M, Merino S, Caro A, Feliu F, Escuder J, et al. (2015) Treatment of colorectal cancer in elderly. World journal of gastrointestinal oncology $7(10)$ : 204-220.

50. Winther BS, Baatrup G, Pfeiffer P, Qvortrup C (2016) Trends in colorectal cancer in the elderly in Denmark, 1980-2012. Acta Oncol 55(Suppl 1): 29-39.

51. Yamano T, Yamauchi S, Kimura K, Babaya A, Hamanaka M, et al. (2017) Influence of age and comorbidity on prognosis and application of adjuvant chemotherapy in elderly Japanese patients with colorectal cancer: a retrospective multicentre study. Eur J Cancer 81: 90-101.

52. Meyers BM, Cosby R, Quereshy F, Jonker D (2017) Adjuvant Chemotherapy for Stage II and III Colon Cancer Following Complete Resection: A Cancer Care Ontario Systematic Review. Clin Oncol (R CollRadiol) 29(7): 459465. 